\title{
Ultrafast Laser Inscription of Buried Waveguides in W- TCP Bioactive Eutectic Glasses
}

\author{
Daniel Sola and José I. Peña \\ Additional information is available at the end of the chapter \\ http://dx.doi.org/10.5772/intechopen.79577
}

\begin{abstract}
Since the first report of Davis in 1996, ultrafast laser inscription (ULI) has been widely used to fabricate buried optical devices such as active and passive waveguides inside dielectric materials. In this technique, ultra-short and ultra-intense laser pulses are tightly focused inside transparent materials leading to laser-induced nonlinear processes in the focal volume. The energy density deposited into the submicron focal volume can reach several of $\mathrm{MJcm}^{-3}$ and hence, may trigger dramatic changes in a strongly localized region, whereas the surrounding bulk material remains unchanged. This technique can be used from void formation to weak refractive index modification, which is the key feature to create buried optical waveguides. In this chapter, firstly, we review the fundamentals of the ultrafast laser inscription technique to produce optical waveguides inside dielectric materials such as crystals and glasses. Next, as an example, we revise the application of this technique to create buried waveguides inside bioactive glasses and specifically, inside W-TCP eutectic glasses.
\end{abstract}

Keywords: ultrafast laser inscription, optical waveguides, integrated photonic devices, rare earth-doped materials, neodymium, bioactive glass, eutectic glass

\section{Introduction}

Since its invention by T.H. Maiman in 1960, the laser interaction with matter has been successfully investigated to find and develop new applications in fundamental, applied, technological and industrial research [1]. Laser materials processing is a versatile tool for materials synthesis, modification and structuring involving in many cases multidisciplinary approaches. Laser technology has been studied in the search for novel applications in research fields such as optics, photonics, energy, microelectronics, aerospace and biomedicine [2-12]. 
The acronym "LASER" stands for "Light Amplification by Stimulated Emission of Radiation" and was first introduced in the late 1950s [13]. Essentially, a laser device is a resonator which emits coherent light originated in a stimulated emission process. A laser resonator or oscillator is usually made up of three main parts: a gain medium which amplifies light by stimulated emission, a pumping source to provide external energy to stimulate the atoms of the gain medium to its excited states, and an optical cavity which supplies feedback to the laser light. The resulting radiation, the laser light, has unique properties such as a high degree of temporal and spatial coherence, and low divergence which confers it of exceptional advantages compared to conventional light sources [14].

Along the last 50 years, laser technology has progressed based on the advances achieved in the development of new gain media, pumping sources and cavity design, leading to many different types of lasers. Attending to the gain medium, lasers can be classified as gas laser, chemical laser, excimer laser, solid-state laser, semiconductor laser, dye laser, free electron laser and metal-vapor laser. According to the laser operation wavelength, the classification can also be as ultraviolet (UV) laser, visible and infrared (IR) laser. In particular, for an operation wavelength between $700 \mathrm{~nm}$ and $2 \mu \mathrm{m}$, the laser is referred as near-infrared (NIR) laser. Also, the classification can be carried out attending to the operation mode; continuous wave (cw) and pulsed lasers [14]. The output power of a cw laser is constant, whereas for a pulsed laser, the power varies pulse-by-pulse. In this latter case, the pulse energy, $E_{p}$, and the peak power, $P_{p^{\prime}}$ can be calculated as:

$$
\begin{aligned}
& E_{p}=P_{\text {out }} / f \\
& P_{p}=E_{p} / \Delta t
\end{aligned}
$$

where $P_{\text {out }}$ is the output power, $f$ is the repetition rate and $\Delta t$ the pulse duration. Therefore, an appropriate combination of both repetition rate and pulse duration may allow pulsed lasers to achieve peak powers much higher than cw lasers. To date, the peak power that a pulsed laser can reach is in the range of a Petawatt with extremely high intensities, in the order of $10^{19} \mathrm{Wcm}^{-2}$, much higher than the atomic unit of intensity $\left(3.510^{16} \mathrm{Wcm}^{-2}\right)$. Hence, ultrashort pulsed lasers have recently attracted scientist's attention aiming at developing novel applications in fields such as biochemistry, spectroscopy, medicine, photonics and telecommunications due to the unique properties of the interaction between ultrashort laser pulses and matter $[2-4,14]$.

After the demonstration of laser action in the ruby laser by Maiman in 1960, for which pumped flash lamp produced a burst of spikes, each several nanoseconds long, that lasted several hundred microseconds, scientists focused their efforts in developing pulsed laser systems with shorter pulse duration. Q-switching was successfully applied in the early 1960s to produce single pulses 10 nanoseconds long [15]. Next, mode-locking technique was first introduced in 1964 for which pulse duration was reduced to 100 picoseconds [16], and by 1981, pulse duration had been reduced down to 100 femtoseconds using the colliding-pulse mode-locking technique [17]. Sub-6 femtosecond pulses were achieved improving passive-mode-locking and dispersion compensation [18-20]. 
Mode-locking is a technique in which a fixed or locked phase relationship between the longitudinal modes of the laser cavity is induced. The longitudinal modes are made to interfere with each other giving rise to the emission of a train of short pulses whose duration may range from few femtoseconds to several picoseconds [21]. The temporal separation between these pulses is the time that a pulse takes to complete one round trip in the resonator cavity. As the duration of a mode-locked laser pulse is very short, according to the time-bandwidth product, its spectrum consists of a broad wavelength range. Mode-locking technique can be active or passive. In active mode-locking, an external signal induces a modulation of the intra-cavity laser radiation by using acousto-optics modulators. Passive mode-locking is based on the introduction in the laser cavity of some elements such as saturable absorbers, dyes or solidstate media which induce self-modulation of the laser light. The most common mode-locked femtosecond lasers are the Ti:Sapphire femtosecond lasers based on the Kerr-Lens Modelocking (KLM) mechanism, in which the Ti:Sapphire gain medium crystal placed inside the cavity acts as Kerr-effect medium [14, 21]. Nowadays, typical commercial femtosecond laser systems produce sub-100 femtoseconds.

\section{Ultrafast laser inscription}

The exceptional characteristics of femtosecond laser pulses have allowed the development of novel applications in the framework of femtosecond laser processing. In particular, the fabrication of two- and three-dimensional permanent structures inside transparent optical materials to be applied in the fields of optics, photonics and telecommunication as key elements such as waveguides, photonic crystals, diffraction gratings, beam splitters, and so on. Since the first report on femtosecond laser written waveguides in glass by Davis et al. [22], different types of integrated optical waveguides have been produced in a great diversity of transparent materials such as glasses, crystals, polycrystalline ceramics and polymers [23-44, 48-67].

In the ultrafast laser inscription (ULI) technique, femtosecond laser pulses are tightly focused beneath the surface. During the absorption process of ultrashort laser pulses, a high local spatial and temporal electronic and vibrational excitation densities are produced which together with the laser pulse duration, short compared to the relevant relaxation processes give rise to laser-induced nonlinear processes in the focal volume, such as two-photon or multiphoton absorption, inducing avalanche ionization in a very short time, leading to localized micro or sub-micrometric lattice damage, modifying the local refractive index and forming the so called "track" or "filament" [3].

The permanent refractive index change $(\Delta n)$ induced in the focal volume has been found to be either positive or negative, depending on the processing parameters and the characteristics of the material. In addition to refractive index modification, a suitable configuration of the femtosecond laser pulses can be used to micromachine small areas by laser ablation or even to create nanovoids inside dielectric materials. The tight focalization in the focal spot can create extreme pressure and temperature conditions, with intensities significantly above the optical breakdown threshold and energy densities of several $\mathrm{MJcm}^{-3}$ into a submicron volume, 
several times higher than the strength of any material. This causes the solid to superheat yielding to the formation of a confined plasma, which explodes and generates a powerful shock wave that expands out of the focal volume and compresses the surrounding material, with pressures over 10 megabar (1 TPa) [45-47]. Therefore, an appropriate combination of the laser processing conditions in terms of numerical aperture $(N A)$, diameter at the focal plane $(d)$, laser wavelength $(\lambda)$, pulse energy $\left(E_{p}\right)$, pulse-width $(\Delta t)$, repetition rate $(f)$, and scanning speed $(V)$ can be used to create a wide variety of laser-induced structures for waveguiding. Specifically, the energy delivered by the laser over each focal spot $d$ is given by:

$$
E_{d}=\frac{f \times d \times E_{p}}{V}
$$

The repetition rate is a critical parameter since the accumulation of multiple laser pulses over the same point will result in a local temperature increase if the period between consecutive pulses $(1 / f)$ is shorter than the cooling time:

$$
t=d^{2} / D
$$

where $D$ is the thermal diffusion coefficient. Thus, there is a critical repetition rate which determines two processing regimes; non-thermal and thermal regime for repetition rate lower and higher than the critical repetition rate [3]. For dielectric materials, thermal diffusivity is in the range of $10^{-3} \mathrm{~cm}^{2} \mathrm{~s}^{-1}$. For a typical laser diameter at the focal plane of around $1 \mu \mathrm{m}$, the critical frequency ranges $100 \mathrm{kHz}$.

It is generally accepted the classification of waveguides structures into four categories according to the structure generated with the laser-induced filament [34]. In Type I waveguides, the laser beam generates a positive refractive index change, $\Delta n>0$, directly in the irradiated area and the hence, the dimensions of the waveguide can be controlled by the amount of energy delivered on the focal volume. This type of waveguide can be induced in glasses since amorphous structure facilitates a positive refractive index change $[3,4,23,36,37]$. On the contrary, the mechanisms involved to be produced in crystals are complicated and entangled and hence, the type of refractive index change and the guiding axis cannot be envisaged. In addition, the damage created by the laser beam in the irradiated area gives rise to a non-desirable strong structural change of the material crystalline network. Furthermore, the waveguiding region is not stable with temperature, and the guidance is only supported in one polarization direction. Therefore, this type of waveguide has been reported in few crystalline materials such as $\mathrm{LiNbO}_{3}, \mathrm{ZnSe}$ and $\mathrm{YCa}_{4} \mathrm{O}\left(\mathrm{BO}_{3}\right)_{3}[35,48-51]$.

In Type II or double-line configuration waveguides, the damage that can be produced by the laser beam in the focal volume is used to create a stress-induced region and a positive refractive index change between two close parallel tracks, normally between 15 and $30 \mu \mathrm{m}$. This type of configuration overcomes the drawbacks of Type I waveguide in crystalline materials so that waveguide structure is stable with temperature, the guidance can be achieved for both laser polarizations and in addition, preserves the luminescence of the bulk material. 
Thus, this waveguide configuration has been widely applied in materials such as Nd:YAG, $\mathrm{Nd}: \mathrm{YVO}_{4^{\prime}} \mathrm{LiNbO}_{3^{\prime}} \mathrm{Yb}: \mathrm{KGd}\left(\mathrm{WO}_{4}\right)_{2^{\prime}} \mathrm{Yb}: \mathrm{KY}\left(\mathrm{WO}_{4}\right)_{2^{\prime}}$ and Nd:Gd $\mathrm{Ga}_{5} \mathrm{O}_{12}[29,31,38,39,50,52,53]$ and glasses [54-58].

The damage and the negative refractive index change originated by the ultra-intense and ultrashort laser radiation can be employed to surround a volume region of the bulk material. This is the origin of Type III or cladding waveguides for which the guiding core is adjusted and tailored by an appropriate position of the low-index tracks, placed few micrometers to each other to confine the light inside. The core diameter normally ranges between 25 and $150 \mu \mathrm{m}$ so that it is possible the guidance of both monomode and multimode laser radiation for both TM and TE polarizations, from the visible to the IR region. These characteristics allow a better coupling to the waveguides, low propagation losses and a more efficient laser action in materials doped with Rare Earths (RE) [40-44, 59-62].

Finally, in Type IV, waveguide also referred as ridge waveguides, the ultra-high intensity achieved by the femtosecond laser pulses is used to ablate the surface to produce ridge waveguides on planar waveguide substrates obtained by other methods. Therefore, the guiding features strongly depend on the planar waveguide substrate [63-67].

In addition to the ULI technique, the fabrication of optical waveguides has also been reported by other processing routes. Among these techniques, it is worth noting ion exchange (IE), annealed proton exchange (APE), molecular beam epitaxy (MBE), liquid phase epitaxy (LPE), and sol-gel [68]. Table 1 shows some examples of optical waveguides manufactured by these methods.

Nevertheless, when compared to these fabrication techniques, ULI has demonstrated to be a very powerful and robust technique due to its versatility, capable of manufacturing waveguides in a great variety of materials, from glasses to crystals, and flexible, allowing to inscribe a broad range of 3D structures and a large variety of waveguide configuration. Furthermore,

\begin{tabular}{llll}
\hline Material & Active ion & Fabrication technique & Reference \\
\hline YAG & $\mathrm{Nd}^{3+} / \mathrm{Yb}^{3+}$ & IE & {$[69]$} \\
$\mathrm{BK7}$ & $\mathrm{Nd}^{3+}$ & $\mathrm{IE}$ & {$[70]$} \\
$\mathrm{LiNbO}_{3}$ & $\mathrm{Nd}^{3+}$ & APE & {$[71]$} \\
$\mathrm{LiTaO}_{3}$ & $\mathrm{Nd}^{3+}$ & APE & {$[72]$} \\
$\mathrm{LaF}_{3}$ & $\mathrm{Nd}^{3+}$ & $\mathrm{MBE}$ & {$[73]$} \\
$\mathrm{CaF}_{2}$ & $\mathrm{Er}^{3+}$ & $\mathrm{MBE}$ & {$[74]$} \\
$\mathrm{GGG}$ & $\mathrm{Nd}^{3+}$ & $\mathrm{LPE}$ & {$[75]$} \\
$\mathrm{KY}\left(\mathrm{WO}_{4}\right)_{2}$ & $\mathrm{Tm}^{3+}$ & LPE & {$[76]$} \\
Silicate glass & $\mathrm{Er}^{3+}$ & Sol-gel & {$[77]$} \\
\hline
\end{tabular}

Table 1. Some examples of optical waveguides manufactured by ion exchange (IE), annealed proton exchange (APE), molecular beam epitaxy (MBE), liquid phase epitaxy (LPE), and sol-gel techniques. 
the fabrication of integrated photonic devices by ULI has shown to be cost-effective and efficient so that a suitable configuration of the processing parameters may lead to waveguide losses below $1 \mathrm{~dB} / \mathrm{cm}$, resulting in a low laser operation threshold.

\section{Ultrashort laser interaction with dielectrics}

The high power density, in the order of tens of $\mathrm{TW} / \mathrm{cm}^{2}$, achieved delivering laser pulses of few microjoules in short period of time, of few femtoseconds, focused beneath the surface in micron-sized areas, results in nonlinear interaction processes. Such high intensities may be manipulated to be employed for modifying the dielectric focal volume, inducing from weak refractive index changes to ultrahigh pressures which lead to void generation. These permanent structural modifications depend not only on the laser peak power but also on the focusing conditions, scanning speed, polarization and repetition rate.

The ultrashort laser-matter interaction process can be divided into three stages: generation of free carriers inside the material by non-linear processes such as multiphoton, tunnel ionization, or avalanche ionization, followed by energy relaxation processes and a subsequent modification of the material [3,4]. The absorption process of ultrashort laser radiation for wide bandgap dielectric materials cannot be explained on the basis of linear absorption, since the photon energy of commonly used femtosecond laser pulses with wavelength between UV and NIR does not have sufficient energy to be linearly absorbed. On the contrary, multiphoton absorption can excite an electron from the valence to the conduction band as long as $m \hbar \omega>E_{g^{\prime}}$ where $m$ is the smallest number of photons for which the overall energy surpasses the bandgap energy $E_{g}$. In addition, tunneling photoionization can also take place under an extremely strong laser electromagnetic field. This mechanism in dielectrics permits electron from the valence band to tunnel to the conduction band in a period of time shorter than the laser pulse. However, in most dielectric multiphoton, ionization dominates the excitation processes [78, 79]. On the other hand, laser photons can be sequentially absorbed by electrons excited in the conduction band by means of free carrier absorption. When the energy of an electron in the excited state exceeds the bandgap energy, the ionization of another electron from the valence band can take place, resulting in two excited electrons at the conduction band minimum. These electrons can be excited again by free carrier absorption processes, and more valence electrons can be produced by the same mechanism, leading to the electronic avalanche $[3,4]$. The requirement for avalanche ionization is the existence of seed electrons in the conduction band, which can be provided by multiphoton or tunneling ionization or by thermally excited impurity or defect states.

Once the nonlinear photoionization and avalanche ionization create a free electron plasma, they transfer their energy to the lattice inducing three types of structural changes: a smooth refractive index modification for low pulse energies such as $100 \mathrm{~nJ}$ and $100 \mathrm{fs}$ at $800 \mathrm{~nm}$ for $0.6 \mathrm{NA}$, a birefringent refractive index modification for pulse energies ranging $150-500 \mathrm{~nJ}$ and $100 \mathrm{fs}$ at $800 \mathrm{~nm}$ for $0.6 \mathrm{NA}$, and microexplosions which result in void formation for pulse energies higher than $500 \mathrm{~nJ}$ and intensities greater than $100 \mathrm{TW} / \mathrm{cm}^{2}[4,78,80]$, Figure 1. The 

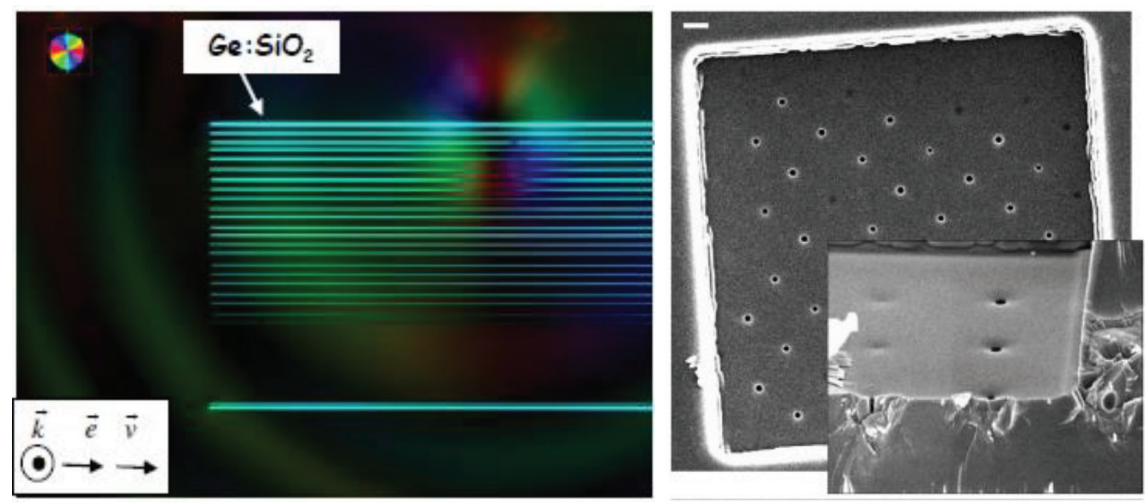

Figure 1. (Left) birefringence cartography in optical fiber Ge-doped preform core [80], and (right) nanovoids in sapphire [46].

type of structural change depends on the laser features (irradiance, repetition rate, polarization), working parameters (scanning speed, numerical aperture) and material properties (thermal conductivity, bandgap energy).

\section{Bioactive glasses}

Formation of glasses with improved properties and manufacturability plays an important role in many technologies. Various noncrystalline materials such as silica glasses, amorphous halides, semiconductors and metals have been used in areas for many engineering applications including biology, communications, electronics, and so on. Glass formation consists basically in avoiding crystallization by cooling from the molten state. The ability to glass formation depends on the melt composition that defines some parameters as glass transition and liquidus temperatures, on the cooling rate which has to be higher enough to avoid the nucleation and growth of the crystalline phases and also on the sample size. As the solidification technique used limits at some extent the cooling rate, the first question in the development of glasses is to determine the composition ranges in which glasses can be obtained under certain cooling conditions (quenching, directional solidification, etc.).

It is known that for multicomponent systems, a strong tendency to glass formation exists near the eutectic points because they have the lower liquidus temperature. Glass formation and its relation to eutectic growth have been investigated for different metal and ceramic alloy systems in terms of the competition between the growth of crystalline phases and the formation of the amorphous phase. The maximum growth rate of a eutectic structure with two or more phases is lower than the maximum growth rate of a single crystalline phase. Therefore, the locations of glass formation in some oxide, halide or metal systems lie near the eutectic area compositions, even though the glass formation also depends on the cooling rate. High 
liquidus slopes, low mutual solubility of the phases (high eutectic range $C_{\alpha \beta}$ ), small diffusion in the melt and large solid/liquid interfacial energies favor the glass formation in competition with the eutectic formed through cooperative growth of the crystalline phases.

Bioactive glasses capable of forming tight chemical bonds to living tissues contain silicates and some of them also phosphates, the first providing a scarcely soluble matrix that compensates for the excess solubility of the latter. The ability of bonding to bone tissue is a result of their chemical reactivity of the surface in a physiological media. The formation of $\mathrm{SiO}_{2}$ rich layer and calcium phosphate film on the surface of a bioglass implanted in a body and bond with living bone was reported by Hench [81]. Kokubo proposed the use of artificial body fluid as a simulated body environment to estimate the bioactivity of the glasses and ceramics [82].

De Aza et al. showed that glasses and ceramics in the systems containing $\mathrm{CaO}-\mathrm{P}_{2} \mathrm{O}_{5}-\mathrm{SiO}_{2}$ can be designed to optimize biological and mechanical response. They have studied different microstructures in the wollastonite $\left(\mathrm{CaO} . \mathrm{SiO}_{2}\right)$-calcium phosphate TCP $\left(3 \mathrm{CaO} . \mathrm{P}_{2} \mathrm{O}_{5}\right)$ system reporting the presence in the phase diagram of an invariant point at $1402^{\circ} \mathrm{C}$ and a composition of $80 \% \mathrm{~mol} \mathrm{~W}$ and $20 \% \mathrm{~mol} \mathrm{TCP}$ [83]. It is possible to estimate the eutectic compositions from the values of melting temperature and heat of fusion of the components through the expressions [84]:

$$
\begin{gathered}
R T \ln X_{i}^{l}=-\Delta H_{i}^{m}\left(1-\frac{T}{T_{i}^{m}}\right) \quad i=1,2,3, \ldots, k \\
\sum_{i=1}^{k} X_{i}^{l}=1
\end{gathered}
$$

where $X_{i}^{l}$ is the mole fraction of component $i$ in the liquid and $T^{m}{ }_{i}$ and $H^{m}{ }_{i}$ are melting temperature and molar heat of fusion of component $i$ in the liquid. The eutectic composition and the eutectic temperature can be calculated with the expressions indicated above if the melting temperature and heats of fusion of the components are known, as shown in Table 2.

On the other hand, in order to form an amorphous solid, the melt must be cooled sufficiently fast to prevent the precipitation of the competitive crystalline phases, defining a minimum cooling rate. Lu and Liu [85] used the dimensionless parameter $\gamma=\mathrm{Tx} /(\mathrm{Tg}+\mathrm{Tl})$ as an indicator of the glass-forming ability of the system, with $\mathrm{Tx}$, Tg and $\mathrm{Tl}$ the crystallization onset, glass transition and melting temperatures, respectively. The relationship between this parameter and the critical cooling rate (Rc) for glass formation is approximately given by the expression:

$$
R_{c}=R_{o} \exp \cdot\left[\left(-\ln R_{o}\right) \gamma / \gamma_{o}\right]
$$

where the constants $R_{o}$ and $\gamma_{\mathrm{o}}$ are, for inorganic glasses, $8 \times 10^{27} \mathrm{~K} / \mathrm{s}$ and 0.421 , respectively. Magallanes-Perdomo et al. described the devitrification and crystallization process of W-TCP eutectic glass, evidencing that the devitrification begins at $870^{\circ} \mathrm{C}$ with the crystallization of a Ca-deficient apatite phase [86]. Being the glass transition temperature $790^{\circ} \mathrm{C}$, the $\gamma$ parameter is 0.414 and the calculated critical cooling rate $R_{c}$ is about $3 \mathrm{~K} / \mathrm{s}$. This rate corresponds to a solidification rate of about $100 \mathrm{~mm} / \mathrm{h}$ in the Laser Floating Zone (LFZ) technique for an experimental axial thermal gradient of $10^{5} \mathrm{~K} / \mathrm{m}$, in good accordance with the growth rate of 


\begin{tabular}{llllllll}
\hline $\mathbf{A}$ & $\mathbf{B}$ & $\begin{array}{l}\mathrm{T}^{\mathrm{m}}{ }_{\mathrm{A}} \\
(\mathbf{K})\end{array}$ & $\begin{array}{l}\mathrm{T}^{\mathrm{m}}{ }_{\mathrm{B}} \\
(\mathbf{K})\end{array}$ & $\begin{array}{l}\mathrm{H}^{\mathrm{m}}{ }_{\mathrm{A}}(\mathrm{J} / \\
\mathbf{m o l})\end{array}$ & $\begin{array}{l}\mathrm{H}^{\mathrm{m}}{ }_{\mathrm{B}}(\mathrm{J} / \\
\mathbf{m o l})\end{array}$ & $\begin{array}{l}\text { Calculated/Measured } \\
\text { eutectic } \mathbf{X}_{\mathrm{A}}-\mathbf{X}_{\mathrm{B}}(\mathbf{m o l} \%)\end{array}$ & $\begin{array}{l}\text { Calculated/Measured } \\
\mathrm{T}_{\text {eut }}(\mathbf{K})\end{array}$ \\
\hline Wollastonite & $\mathrm{TCP}$ & 1821 & 1943 & 36.844 & 156.057 & $80.25-20.61$ & $1670 / 1675$ \\
& & & & & & $80-20$ & \\
\hline
\end{tabular}

Table 2. Calculated eutectic composition and temperature in W-TCP system.

$150 \mathrm{~mm} / \mathrm{h}$ reported by Pardo et al. for the fabrication of a W-TCP eutectic glass rod of $3 \mathrm{~mm}$ in diameter [87]. A detailed description of this technique can be consulted elsewhere [88, 89].

This eutectic glass, produced by the laser floating zone technique, is chemically stable and has a high optical quality being able to be used as a matrix for luminescence active ions. This composition corresponds to an "invert" glass where the modifier content (Ca) is larger than the former content $(\mathrm{Si}+\mathrm{P})$. This term was introduced by Trapp and Stevels [90] because the traditional network forming oxides $\mathrm{SiO}_{2}$ and $\mathrm{P}_{2} \mathrm{O}_{5}$ form continuous molecular/ionic networks in normal conditions; however, when the network modifying oxides are in majority on the molar basis, the glasses are structurally inverted compared to conventional glasses. This structural inversion is reflected in the properties of the glasses. In addition, the optical properties of this glass doped with $\mathrm{Nd}^{3+}$ and $\mathrm{Er}^{3+}$ ions have been assessed, resulting in emission crosssections and lifetimes similar to those reported for the best commercial alkaline-silicate glasses [87]. Furthermore, the incorporation of trivalent rare-earth (RE) ions can also be used as local ordering probe due to the close relation between their spectroscopic properties and the local structure and bonding at the ion site, since the spectroscopic properties of trivalent rare-earth ions depend on the chemical composition of the glass matrix, which determines the structure and nature of the bonds, and thus spectroscopic characterization allows studying the local structure surrounding the RE ion and the covalence of the RE-O bond [91, 92]. In particular, site-selective excitation and emission of $\mathrm{Nd}$ - and Eu-doped $\mathrm{W}$-TCP glass ceramics provided information about the differences on the spectral features of amorphous and crystalline environments in this matrix, allowing the identification by means of Raman and LIBS of crystalline phases corresponding to dicalcium silicate $\left(\mathrm{Ca}_{2} \mathrm{SiO}_{4}\right)$ and apatite-like structures, both with well-known bioactive and biocompatible properties [93-95]. These results showed the potential applications of these materials obtained from the LFZ technique as luminescence bioprobes for in vitro applications and promote extended studies to other rare-earth ions, which can be used in biomedical applications such as multicolor bioprobes and biosensors among others.

\section{Fabrication of photonic devices in $\mathrm{W}$-TCP bioactive glasses}

Both stress-induced and depressed cladding waveguides have been studied in Nd-doped $\mathrm{CaSiO}-\mathrm{Ca}_{3}\left(\mathrm{PO}_{4}\right)_{2}$ bioactive glasses. In both cases, the guiding structures were manufactured by using the ULI technique. For this purpose, a tunable Ti:Sapphire laser emitting at the central wavelength of $795 \mathrm{~nm}$ with $120 \mathrm{fs}$ laser pulses and $1 \mathrm{kHz}$ repetition rate was used. Figure 2 shows an example of double-line configuration and a depressed cladding waveguide obtained in this glass, (a) and (b), respectively. For the case of the stress-induced waveguide, 

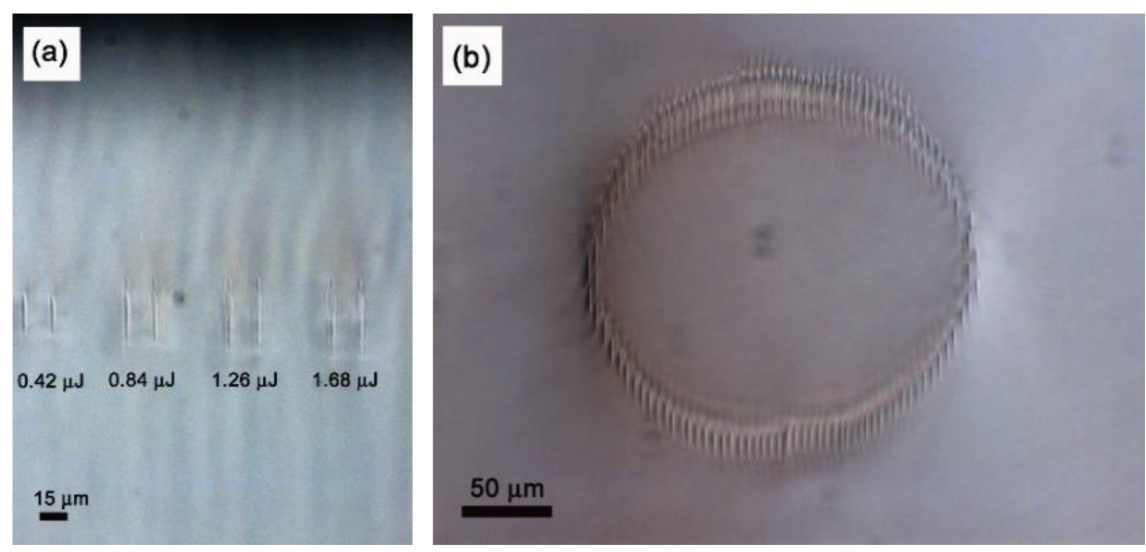

Figure 2. Double-line (a) and depressed cladding (b) waveguides produced in the W-TCP eutectic bioactive glass $[56,60]$.

the guiding characteristics were studied modifying the pulse energy between 0.42 and $1.68 \mu \mathrm{J}$, the scanning speed at 25 and $50 \mu \mathrm{m} / \mathrm{s}$ and the distance between filaments at 15 and $20 \mu \mathrm{m}$. Also, in this case, the structures were inscribed at 150 and $250 \mu \mathrm{m}$ beneath the surface of the sample. As shown in Figure 2(a), the filament dimensions strongly depend on the energy delivered $\left(E_{d}\right)$ by the laser beam, between 8.4 and $67 \mu \mathrm{J}$, achieving lengths from 16 up to $40 \mu \mathrm{m}$. For the case of the cladding structure, both the distance between filaments and the scanning speed were set constant at $3 \mu \mathrm{m}$ and $500 \mu \mathrm{m} / \mathrm{s}$ respectively, studying the guiding properties with the diameter of the core, between 20 and $150 \mu \mathrm{m}$, and the depth from the surface, 300 and $600 \mu \mathrm{m}$. Worth mentioning is the fact that the fabrication of cladding structures required lower delivered energy than in the case of double-filament waveguides, since the filaments were very close to each other and an excessive amount of energy might create cracks on the irradiated area and hence to fracture the sample. Specifically, in this case, filaments of the cladding structure were produced delivering $1.44 \mu \mathrm{J}$ over each focal spot. In addition, the interaction of the ultrashort laser radiation with the glass sample gave rise to an affected zone in the surroundings of the tracks, caused by the generation of color centers. It is well known that high intensity ultrashort laser pulses may modify the properties of the material at atomic scale by the photophysical and photochemical interactions which take place after the laser absorption [3]. These color centers also may affect to both the guiding and luminescence properties.

The guiding properties were assessed by characterization of the near-field intensity distribution with a continuous wave He-Ne laser at $633 \mathrm{~nm}$. Both types of waveguides presented TE and TM propagation. Furthermore, all double-filament waveguides inscribed were found to be monomode, whereas only $20 \mu \mathrm{m}$ diameter depressed cladding waveguides presented this feature. In addition, for double-filament waveguides, the width found in TE and TM modes was shorter along the $x$-axis than in the orthogonal one, but the modal area decreased with the pulse energy thus increasing the light confinement. Moreover, the best confinement conditions were achieved for both the shortest track distance $(15 \mu \mathrm{m})$ and depth $(150 \mu \mathrm{m})$, and the highest scanning speed $(50 \mu \mathrm{m} / \mathrm{s})$. Concerning the cladding waveguides, there were no remarkable differences depending either on the guided polarization or processing 
parameters. As an example, Figure 3 shows the near-field distribution intensity of TE mode in a double-filament waveguide inscribed $150 \mu \mathrm{m}$ beneath the surface with $15 \mu \mathrm{m}$ between tracks (a), and cladding waveguides (b) of $20 \mu \mathrm{m}$ (left) and $30 \mu \mathrm{m}$ (right) diameters.

The absorption generated by color centers, appeared during the laser inscription process was reduced by means of isochronal heat treatments thus decreasing propagation losses [96-98]. This annealing process produced an improvement of up to a $29 \%$ in the transmitted power in the range of $300-350^{\circ} \mathrm{C}$ for the double-line waveguide, as shown in Figure 4(a), whereas higher annealing temperatures led to a diminution of the stress-induced between filaments and therefore to a decrease in the refractive index change and consequently in the light confinement. In depressed cladding waveguides, the thermal treatment induced a continuous improvement of the transmitted intensity up to $650^{\circ} \mathrm{C}$, based on a gradual removal of color centers and a partial recovery of the refractive index change caused by the release of the stress-induced by the ultrashort laser pulses. Annealing temperatures higher than $650^{\circ} \mathrm{C}$ reduced the optical barrier and the tunneling losses became non-negligible [99]. The analysis of the evolution of the modal intensity as a function of the thermal treatment temperature confirmed this mechanism, as shown in Figure 4(b), revealing that the light confinement kept almost unaltered until $600^{\circ} \mathrm{C}$, whereas higher temperatures enlarged the modes hindering the light transmission.

Luminescence characterization carried out in both types of waveguides revealed that spectroscopic properties were well preserved in the volume of the waveguides and that annealing treatment at high temperature recombined the damaged produced in the irradiated areas, resulting in a worsening the light confinement. Fluorescence lifetimes, around 240-250 $\mathrm{s}$, and both luminescence spectra and $\mu \mathrm{L}$ map of the ${ }^{4} \mathrm{~F}_{3 / 2} \rightarrow{ }^{4} \mathrm{I}_{11 / 2}$ transition in the bulk and in the waveguide's volume pointed out no significant modifications, Figure 5.

The refractive index modification was estimated on the basis of the refractive index distribution generated by femtosecond laser pulses in double-filament waveguides [100, 101], for which:

$$
\Delta n=-\Delta n_{\max } \frac{1-\left(x / \sigma_{x}\right)^{2}}{1+\left(x / \sigma_{x}\right)^{4}} \exp \left(x / \sigma_{y}\right)^{2}
$$
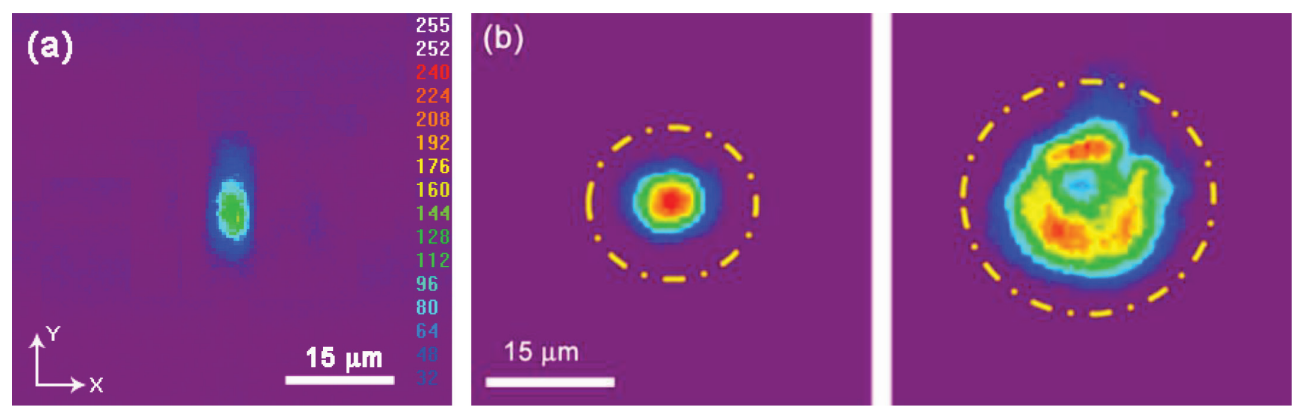

Figure 3. Near-field distribution intensity of TE mode in a double-filament waveguide with $15 \mu \mathrm{m}$ between tracks (a) and in depressed cladding waveguides (b) $20 \mu \mathrm{m}$ (left) and $30 \mu \mathrm{m}$ (right) diameter produced in the W-TCP eutectic bioactive glass $[56,60]$. 
(a)

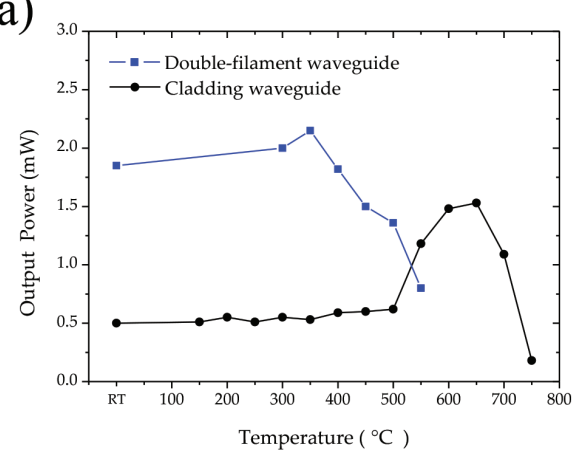

(b)

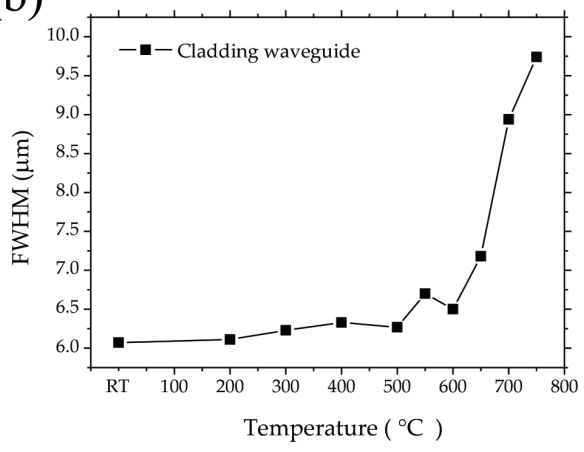

Figure 4. (a) Output power measured in double-filament and depressed cladding waveguides after isochronal heat treatment between room temperature (RT) and $750^{\circ} \mathrm{C}$. (b) Evolution of the FWHM TE mode as a function of the annealing temperature between room temperature (RT) and $750^{\circ} \mathrm{C}$ for the $20 \mu \mathrm{m}$ diameter cladding waveguide $[56,60]$.
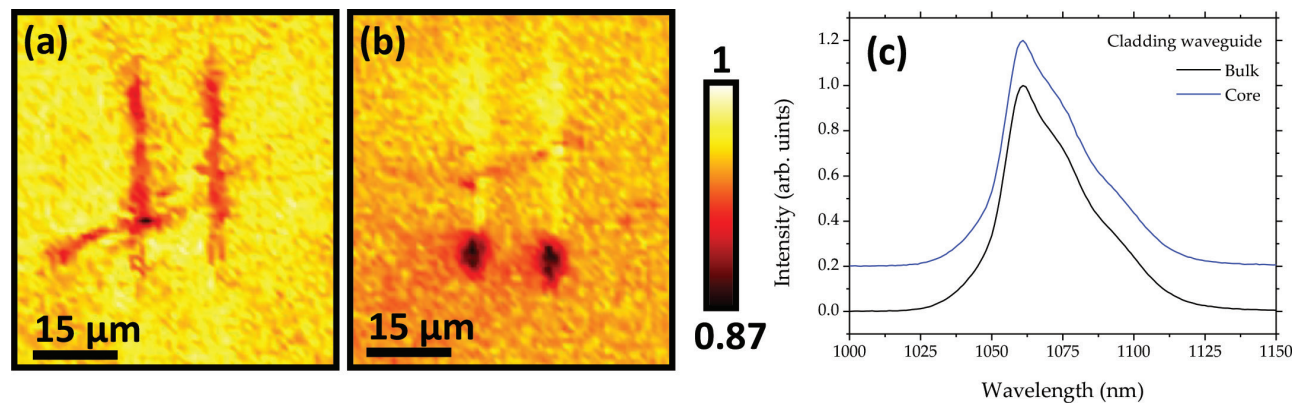

Figure 5. Spatial variation of the $\mathrm{Nd}^{3+}$ fluorescence intensity for a double-filament waveguide at room temperature (a) and at $550^{\circ} \mathrm{C}(\mathrm{b})$ and emission of $\mathrm{Nd}^{3+}$ at $1060 \mathrm{~nm}$ under excitation at $808 \mathrm{~nm}$ for a $20 \mu \mathrm{m}$ diameter depressed cladding waveguide in the core of the waveguide and in the bulk [56, 60].

where $\Delta n_{\max }$ is the maximum reduction on the refractive index in the track, and $\sigma_{x}$ and $\sigma_{y}$ are the width of the damaged region along the horizontal and vertical directions respectively, resulting in a $\Delta n \sim 5 \times 10^{-3}$, which was found to be in the same range of previously reported for other waveguides inscribed by femtosecond laser writing, such as Nd:YAG ceramics, $\mathrm{Nd}: \mathrm{YVO}_{4}$ and fused-silica.

\section{Conclusions}

Fabrication of integrated photonic devices has been a hot topic in research since the first report on femtosecond laser written waveguides in glass by using the Ultrafast Laser Inscription Technique (ULI), in 1996. In this chapter, we have reviewed the fundamentals of this laser 
processing technique, describing the main configurations for waveguide fabrication achieved to date, and the materials for which they have been applied. Also, a comparison to other techniques commonly used for waveguide fabrication has been included, pointing out the principal advantages of ULI when compared to these methods. Furthermore, the basis of the interaction between ultrashort laser pulses and dielectric media which may give rise to refractive index modification and hence, to waveguide fabrication has been outlined. In addition, this chapter briefly reviews the development of bioactive glasses related to their capability of forming tight chemical bonds to living tissues. This section is particularized to the development of $\mathrm{CaSiO}_{3}-\mathrm{Ca}_{3}\left(\mathrm{PO}_{4}\right)_{2}$ bioactive eutectic glass and glass ceramics, and to their potential applications as luminescence bioprobes in biomedical applications when doped with rareearth ions. Finally, this chapter reviews the fabrication of double-filament and depressed cladding waveguides in Nd-doped $\mathrm{CaSiO}-\mathrm{Ca}_{3}\left(\mathrm{PO}_{4}\right)_{2}$ bioactive eutectic glasses. Doublefilament waveguides presented an increase of the refractive index in the region between damaged areas, the so-called "tracks," inscribed with the ultrashort laser pulses. In cladding waveguides, tracks were inscribed close to each other to surround a volume of bulk material. Both types of waveguides supported TE and TM polarization guiding under illumination of cw He-Ne laser radiation. In particular, only the cladding waveguide with the smallest core, $20 \mu \mathrm{m}$, presented monomode transmitted light. Color centers formation was observed in both types of waveguides as a consequence of the laser interaction with the glass. Isochronal thermal treatments allowed decreasing the absorption by color centers and for the highest annealing temperatures, a release of the stress-induced in the laser treated area. In addition, it was shown that spectroscopic properties were well preserved in the volume of the waveguides. Finally, the refractive index modification, $\Delta n$, was estimated in $5 \times 10^{-3}$, in the same range of previously reported works by the ULI technique.

Future work is expected to be done in the fabrication of integrated photonic devices in glasses and glass ceramics of the $\mathrm{CaO}-\mathrm{P}_{2} \mathrm{O}_{5}-\mathrm{SiO}_{2}-\mathrm{MgO}$ system by the ULI technique. Glasses and glass ceramics of this system are also bioactive. Therefore, we will ascertain and assess the optimal conditions for the fabrication of optical waveguides and their possible utilization as laser sources for biomedical applications.

\section{Acknowledgements}

Dr. Daniel Sola thanks the Ministry of Economy and Competitiveness of the State General Administration under the project MINECO FIS2016-76163-R and the PIT2 program of the University of Murcia's own research plan for the financial support of his contract.

\section{Conflict of interest}

The authors declare no conflict of interest. 


\section{Author details}

Daniel Sola ${ }^{1 *}$ and José I. Peña ${ }^{2}$

*Address all correspondence to: daniel.sola@um.es

1 Laboratorio de Optica (LO·UM), Center of Research in Optics and Nano-physics (CIOyN), University of Murcia, Murcia, Spain

2 Materials Science Institute of Aragon (ICMA), University of Zaragoza-CSIC, Zaragoza, Spain

\section{References}

[1] Maiman TH. Stimulated optical radiation in ruby. Nature. 1960;187:493-494. DOI: 10. 1038/187493a0

[2] Bäuerle D. Laser Processing and Chemistry. 3rd ed. Berlin: Springer-Verlag; 2000. DOI: 10.1007/978-3-642-17613-5

[3] Misawa H, Juodkazis S, editors. 3D Laser Microfabrication: Principles and Applications. Weinheim: Wiley-VCH; 2006. DOI: 10.1002/352760846X.ch10

[4] Osellame R, Cerullo G, Ramponi R, editors. Femtosecond Laser Micromachining: Photonic and Microfluidic Devices in Transparent Materials. Berlin: Springer; 2012. DOI: 10.1007/978-3-642-23366-1

[5] Sola D, Peña JI. Foamy coating obtained by laser ablation of glass ceramic substrates at high temperature. Applied Surface Science. 2009;255:5322-5328. DOI: 10.1016/j.apsusc. 2008.09.028

[6] Gurauskis J, Sola D, Peña JI, Orera VM. Laser drilling of Ni-YSZ cermets. Journal of the European Ceramic Society. 2008;28:2673-2680. DOI: 10.1016/j.jeurceramsoc.2008.04.012

[7] Sola D, Escartín A, Cases R, Peña JI. Crystal growth induced by Nd:YAG laser irradiation in patterning glass ceramic substrates with dots. Optical Materials. 2011;33:728-734. DOI: 10.1016/j.optmat.2010.11.008

[8] Sola D, Peña JI. Laser machining of $\mathrm{Al}_{2} \mathrm{O}_{3}-\mathrm{ZrO}_{2}\left(3 \% \mathrm{Y}_{2} \mathrm{O}_{3}\right)$ eutectic composite. Journal of the European Ceramic Society. 2012;32:807-814. DOI: 10.1016/j.jeurceramsoc.2011.11.007

[9] Sola D, Peña JI. Study of the wavelength dependence in laser ablation of advanced ceramics and glass-ceramic materials in the nanosecond range. Materials. 2013;6:5302-5313. DOI: $10.3390 / \mathrm{ma} 6115302$

[10] Garcia-Giron A, Sola D, Peña JI. Liquid-assisted laser ablation of advanced ceramics and glass-ceramic materials. Applied Surface Science. 2016;363:548-554. DOI: 10.1016/j. apsusc.2015.12.079 
[11] Sola D, Grima L. Laser machining and in vitro assessment of wollastonite-tricalcium phosphate eutectic glasses and glass-ceramics. Materials. 2018;11:125. DOI: 10.3390/ ma11010125

[12] Sola D, Lavieja C, Orera A, Clemente MJ. Direct laser interference patterning of ophthalmic polydimethylsiloxane (PDMS) polymers. Optics and Lasers in Engineering. 2018;106:139-146. DOI: 10.1016/j.optlaseng.2018.03.007

[13] Bromberg JL. The birth of the laser. Physics Today. 1988;41:26-33. DOI: 10.1063/1.881155

[14] Svelto O. Principles of Lasers. 5th ed. New York: Springer; 2010. DOI: 10.1007/9781-4419-1302-9

[15] McClung FJ, RW, Hellwarth RW. Giant optical pulsations from ruby. Journal of Applied Physics. 1962;33:828. DOI: 10.1063/1.1777174

[16] Hargrove LE, Fork RL, Pollack MA. Locking of he-ne laser modes induced by synchronous intracavity modulation (diffraction by phonons in crystals E). Applied Physics Letters. 1964;5:4-5. DOI: 10.1063/1.1754025

[17] Fork RL, Greene BI, Shank CV. Generation of optical pulses shorter than 0.1 psec by colliding pulse mode locking. Applied Physics Letters. 1981;38:671-672. DOI: 10.1063/1.92500

[18] Morgner U, Kärtner FX, Cho SH, Chen Y, Haus HA, Fujimoto JG, Ippen EP. Sub-twocycle pulses from a Kerr-lens mode-locked Ti:Sapphire laser. Optics Letters. 1999;24: 411-413. DOI: 10.1364/OL.24.000411

[19] Morgner U, R Ell R, Metzler G, Schibli TR, Kärtner FX, Fujimoto JG, Haus HA, Ippen EP. Nonlinear optics with phase-controlled pulses in the sub-two-cycle regime. Physical Review Letters 2001;86:5462-5465. DOI: 10.1103/PhysRevLett.86.5462

[20] Gallman L, Sutter DH, Matuschek N, Steinmeyer G, Keller U, Iaconis C, Walmsley IA. Characterization of sub-6-fs optical pulses with spectral phase interferometry for direct electric-field reconstruction. Optics Letters. 1999;24:1314-1316. DOI: 10.1364/OL. 24.001314

[21] Rulliere C. Femtosecond Laser Pulses: Principles and Experiments. 2nd ed. New York: Springer; 2003. DOI: 10.1007/b137908

[22] Davis KM, Miura K, Sugimoto N, Hirao K. Writing waveguides in glass with a femtosecond laser. Optics Letters. 1996;21:1729-1731. DOI: 10.1364/OL.21.001729

[23] Nolte S, Will M, Burghoff J, Tuennermann A. Femtosecond waveguide writing: A new avenue to three-dimensional integrated optics. Applied Physic A. 2003;7:109-111. DOI: 10.1007/s00339-003-2088-6

[24] Taccheo S, Della Valle G, Osellame R, Cerullo G, Chiodo N, Laporta P, Svelto O, Killi A, Morgner U, Lederer M, Kopf D. Er:Yb-doped waveguide laser fabricated by femtosecond laser pulses. Optics Letters. 2004;29:2626-2628. DOI: 10.1364/OL.29.002626 
[25] Zhou G, Gu M. Direct optical fabrication of three-dimensional photonic crystals in a high refractive index $\mathrm{LiNbO}_{3}$ crystal. Optics Letters. 2006;31:2783-2785. DOI: 10.1364/ OL.31.002783

[26] Thomson RR, Bookey HT, Psaila ND, Fender A, Campbell S, MacPherson WN, Barton JS, Reid DT, Kar AK. Ultrafast-laser inscription of a three dimensional fan-out device for multicore fiber coupling applications. Optics Express. 2007;15:11691-11697. DOI: 10.1364/ OE.15.011691

[27] Psaila ND, Thomson RR, Bookey HT, Kar AK, Chiodo N, Osellame R, Cerullo G, Jha A, Shen S. Er: Yb-doped oxyfluoride silicate glass waveguide amplifier fabricated using femtosecond laser inscription. Applied Physics Letters 2007;90:131102. DOI: 10.1063/ 1.2716866

[28] Torchia GA, Rodenas A, Benayas A, Cantelar E, Roso L, Jaque D. Highly efficient laser action in femtosecond-written $\mathrm{Nd}$ :Yttrium aluminum garnet ceramic waveguides. Applied Physics Letters. 2008;92:111103. DOI: 10.1063/1.2890073

[29] Siebenmorgen J, Petermann K, Huber G, Rademaker K, Nolte S, Tünnermann A. Femtosecond laser written stress-induced $\mathrm{Nd}: \mathrm{Y}_{3} \mathrm{Al}_{5} \mathrm{O}_{12}(\mathrm{Nd}: \mathrm{YAG})$ channel waveguide laser. Applied Physics B. 2009;97:251-255. DOI: 10.1007/s00340-009-3697-3

[30] Siebenmorgen J, Calmano T, Petermann K, Huber G. Highly efficient Yb:YAG channel waveguide laser written with a femtosecond-laser. Optics Express. 2010;18:16035106041. DOI: 10.1364/OE.18.016035

[31] Silva WF, Jacinto C, Benayas A, Vazquez de Aldana JR, Torchia GA, Chen F, Tan Y, Jaque D. Femtosecond-laser-written, stress-induced $\mathrm{Nd}: \mathrm{YVO}_{4}$ waveguides preserving fluorescence and Raman gain. Optics Letters. 2010;35:916-918. DOI: 10.1364/OL.35.000916

[32] Fletcher LB, Witcher JJ, Troy N, Reis SR, Brow RK, Martinez Vazquez R, Osellame R, Krol DM. Femtosecond laser writing of waveguides in zinc phosphate glasses. Optical Materials Express. 2011;1:845-855. DOI: 10.1364/OME.1.000845

[33] Benayas A, Silva WF, Rodenas A, Jacinto C, Vazquez de Aldana J, Chen F, Tan Y, Thomsom RR, Psaila ND, Red DT, Torchia GA, Kar AK, Jaque D. Ultrafast laser writing of optical waveguides in ceramic Yb:YAG: A study of thermal and non-thermal regimes. Applied Physics A. 2011;104:301-309. DOI: 10.1007/s00339-010-6135-9

[34] Chen F, Vázquez de Aldana JR. Optical waveguides in crystalline dielectric materials produced by femtosecond-laser micromachining. Laser and Photonics Review. 2014;8:251-275. DOI: 10.1002/lpor.201300025

[35] Li L, Nie W, Li Z, Romero C, Rodriguez-Beltrán RI, Vázquez De Aldana JR, Chen F. Laser-writing of ring-shaped waveguides in BGO crystal for telecommunication band. Optics Express. 2017;25:24236-24241. DOI: 10.1364/OE.25.024236

[36] McMillen B, Zhang B, Chen KP, Benayas A, Jaque D. Ultrafast laser fabrication of lowloss waveguides in chalcogenide glass with $0.65 \mathrm{~dB} / \mathrm{cm}$ loss. Optics Letters. 2012;37:14181420. DOI: $10.1364 /$ OL.37.001418 
[37] Morris JM, Mackenzie MD, Petersen CR, Demetriou G, Kar AK, Bang O, Bookey HT. $\mathrm{Ge}_{22} \mathrm{As}_{20} \mathrm{Se}_{58}$ glass ultrafast laser inscribed waveguides for mid-IR integrated optics. Optical Materials Express. 2018;8:1001-1011. DOI: 10.1364/OME.8.001001

[38] Lv J, Cheng Y, Lu Q, Vázquez De Aldana JR, Hao X, Chen F. Femtosecond laser written optical waveguides in z-cut $\mathrm{MgO}: \mathrm{LiNbO}_{3}$ crystal: Fabrication and optical damage investigation. Optical Materials. 2016;57:169-173. DOI: 10.1016/j.optmat.2016.05.003

[39] Morris J, Stevenson NK, Bookey HT, Kar AK, Brown CTA, Hopkins J-M, Dawson MD, Lagatsky AA. $1.9 \mu \mathrm{m}$ waveguide laser fabricated by ultrafast laser inscription in tm: $\mathrm{Lu}_{2} \mathrm{O}_{3}$ ceramic. Optics Express. 2017;25:14910-14917. DOI: 10.1364/OE.25.014910

[40] Ren Y, Zhang L, Xing H, Romero C, Vázquez de Aldana JR, Chen F. Cladding waveguide splitters fabricated by femtosecond laser inscription in Ti:Sapphire crystal. Optics and Laser Technology. 2018;103:82-88. DOI: 10.1016/j.optlastec.2018.01.021

[41] Li R, Nie W, Lu Q, Cheng C, Shang Z, Vázquez de Aldana JR, Chen F. Femtosecondlaser-written superficial cladding waveguides in $\mathrm{Nd}: \mathrm{CaF}_{2}$ crystal. Optics and Laser Technology. 2017;92:163-167. DOI: 10.1016/j.optlastec.2017.01.026

[42] Kifle E, Mateos X, Vázquez De Aldana JR, Ródenas A, Loiko P, Choi SY, Rotermund F, Griebner U, Petrov V, Aguiló M, Díaz F. Femtosecond-laser-written tm:KLu( $\left(\mathrm{WO}_{4}\right)_{2}$ waveguide lasers. Optics Letters. 2017;42:1169-1172. DOI: 10.1364/OL.42.001169

[43] Nguyen H-D, Ródenas A, De Aldana JRV, Martínez J, Chen F, Aguiló M, Pujol MC, Díaz F. Heuristic modelling of laser written mid-infrared LiNbO3 stressed-cladding waveguides. Optics Express. 2016;24:7777-7791. DOI: 10.1364/OE.24.007777

[44] Thorburn F, Lancaster A, McDaniel S, Cook G, Kar AK. 5.9 GHz graphene based q-switched modelocked mid-infrared monolithic waveguide laser. Optics Express. 2017;25:26166-26174. DOI: 10.1364/OE.25.026166

[45] Glezer E, Mazur E. Ultrafast-laser driven micro-explosions in transparent materials. Applied Physics Letters. 1997;71:882-884

[46] Gamaly EG, Juodkazis S, Nishimura K, Misawa H, Luther-Davis B, Hallo L, Nicolai P, Tikhonchuk V. Laser-matter interaction in the bulk of a transparent solid: Confined microexplosion and void formation. Physical Review B 2006;73:214101-1 214101-15.

[47] Vailionis A, Gamaly EG, Mizeikis V, Yang W, Rode AV, Juodkazis S. Evidence of superdense aluminium synthesized by ultrafast microexplosion. Nature Communications. 2011;2:445-451

[48] Macdonald TRR, Beecher SJ, Psaila ND, Bookey HT, Kar AK. Ultrafast laser inscription of near-infrared waveguides in polycrystalline ZnSe. Optics Letters. 2010;35:4036-4038. DOI: 10.1364/OL.35.004036

[49] Rodenas A, Kar AK. High-contrast step-index waveguides in borate nonlinear laser crystals by 3D laser writing. Optics Express. 2011;19:17820-17833. DOI: 10.1364/OE.19.017820 
[50] Burghoff J, Nolte S, Tunnermann A. Origins of waveguiding in femtosecond laserstructured $\mathrm{LiNbO}_{3}$. Applied Physics A. 2007;89:127-132. DOI: 10.1007/s00339-007-4152-0

[51] Heinrich M, Rademaker K, Nolte S. Waveguides in crystalline materials. In: FemtosecondLaser Micromachining: Photonic and Microfluidic Devices in Transparent Materials. Berlin: Springer; 2012. pp. 295-313. DOI: 10.1007/978-3-642-23366-1

[52] Bain FM, Lagatsky AA, Thomson RR, Psaila ND, Kuleshov NV, Kar AK, Sibbett W, Brown CTA. Ultrafast laser inscribed $\mathrm{Yb}: \mathrm{KGd}\left(\mathrm{WO}_{4}\right)_{2}$ and $\mathrm{Yb}: \mathrm{KY}\left(\mathrm{WO}_{4}\right)_{2}$ channel waveguide lasers. Optics Express. 2009;17:22417-22422

[53] Zhang C, Dong N, Yang J, Chen F, Vázquez de Aldana JR, Lu Q. Channel waveguide lasers in Nd:GGG crystals fabricated by femtosecond laser inscription. Optics Express. 2011;19:12503-12508. DOI: 10.1364/OE.19.012503

[54] Bhardwaj VR, Corkum PB, Rayner DM, Hnatovsky C, Simova E, Taylor RS. Stress in femtosecond-laser-written waveguides in fused silica. Optics Letters. 2004;29:1312-1314. DOI: $10.1364 /$ OL.29.001312

[55] Fernandes LA, Grenier JR, Herman PR, Aitchison JS, Marques PVS. Stress induced birefringence tuning in femtosecond laser fabricated waveguides in fused silica. Optics Express. 2012;20:24103-24114. DOI: 10.1364/OE.20.024103

[56] Sola D, de Mendibil JM, de Aldana JRV, Lifante G, Balda R, de Aza AH, Pena P, Fernandez J. Stress-induced buried waveguides in the $0.8 \mathrm{CaSiO}-0.2 \mathrm{Ca}_{3}\left(\mathrm{PO}_{4}\right)_{2}$ eutectic glass doped with $\mathrm{Nd}^{3+}$ ions. Applied Surface Science. 2013;278:289-294. DOI: 10.1016/j. apsusc.2013.01.060

[57] Beresna M, Gecevičius M, Kazansky PG. Ultrafast laser direct writing and nanostructuring in transparent materials. Advances in Optics and Photonics. 2014;6:293-339. DOI: 10.1364/AOP.6.000293

[58] Zhang YJ, Zhang GD, Bai J, Chen CL, Stoian R, Cheng GH. Double line and tubular depressed cladding waveguides written by femtosecond laser irradiation in PTR glass. Optical Materials Express. 2017;7:2626-2635. DOI: 10.1364/OME.7.002626

[59] Okhrimchuk AG, Shestakov AV, Khrushchev I, Mitchell J. Depressed cladding, buried waveguide laser formed in a YAG: $\mathrm{Nd}^{3+}$ crystal by femtosecond laser writing. Optics Letters. 2005;30:2248-2250. DOI: 10.1364/OL.30.002248

[60] Martínez de Mendívil J, Sola D, Vázquez de Aldana JR, Lifante G, de Aza AH, Pena P, Peña JI. Ultrafast direct laser writing of cladding waveguides in the $0.8 \mathrm{CaSiO}-0.2 \mathrm{Ca}_{3}\left(\mathrm{PO}_{4}\right)_{2}$ eutectic glass doped with $\mathrm{Nd}^{3+}$ ions. Journal of Applied Physics. 2015;117:4906963. DOI: $10.1063 / 1.4906963$

[61] Okhrimchuk A, Mezentsev V, Shestakov A, Bennion I. Low loss depressed cladding waveguide inscribed in YAG:Nd single crystal by femtosecond laser pulses. Optics Express. 2012;20:3832-3843. DOI: 10.1364/OE.20.003832

[62] An Q, Jia Y, Liu H, De Aldana JRV, Chen F. Ultrafast laser inscribed cladding waveguides in Nd:YAG crystal for mid-infrared wavelength. Optics and Laser Technology. 2014;56:382-386. DOI: 10.1016/j.optlastec.2013.09.011 
[63] Li L, Nie W, Li Z, Lu Q, Romero C, Vázquez De Aldana JR, Chen F. All-laser-micromachining of ridge waveguides in $\mathrm{LiNbO}_{3}$ crystal for mid-infrared band applications. Scientific Reports. 2017;7:7034. DOI: 10.1038/s41598-017-07587-w

[64] Martínez de Mendívil J, del Hoyo J, Solís J, Lifante G. Ridge waveguide laser in Nd:LiNbO by Zn-diffusion and femtosecond-laser structuring. Optical Materials 2016;62:353-356. DOI: $10.1016 /$ j.optmat.2016.10.008

[65] Jia Y, Dong N, Chen F, Vázquez de Aldana JR, Akhmadaliev S, Zhou S. Continuous wave ridge waveguide lasers in femtosecond laser micromachined ion irradiated Nd:YAG single crystals. Optical Materials Express. 2012;2:657-662. DOI: 10.1364/OME.2.000657

[66] Jia Y, Dong N, Chen F, Vázquez de Aldana JR, Akhmadaliev S, Zhou S. Ridge waveguide lasers in Nd:GGG crystals produced by swift carbon ion irradiation and femtosecond laser ablation. Optics Express. 2012;20:9763-9768. DOI: 10.1364/OE.20.009763

[67] Martínez De Mendívil J, Hoyo J, Solis J, Pujol MC, Aguiló M, Diaz F, Lifante G. Channel waveguide fabrication in $\mathrm{KY}\left(\mathrm{WO}_{4}\right)_{2}$ combining liquid-phase-epitaxy and beam-multiplexed femtosecond laser writing. Optical Materials. 2015;45:304-309. DOI: 10.1016/j. optmat.2015.05.046

[68] Cantelar E, Jaque D, Lifante G. Waveguide lasers based on dielectric materials. Optical Materials. 2012;34:555-571. DOI: 10.1016/j.optmat.2011.05.012

[69] Sugimoto N, Ohishi Y, Katoh Y, Tate A, Shimokozono M, Sudo S. A ytterbium- and neodymium-co-doped yttrium aluminum garnet-buried channel waveguide laser pumped at 0.81 $\mu \mathrm{m}$. Applied Physics Letters. 1995;67:582-584. DOI: 10.1063/1.115395

[70] Hettrick SJ, Mackenzie JI, Harris RD, Wilkinson JS, Sheppherd DP, Tropper AC. Ionexchanged tapered-waveguide laser in neodymium-doped BK7 glass. Optics Letters. 2000;25:1433-1435. DOI: 10.1364/OL.25.001433

[71] Lallier E, Pocholle JP, Papuchon M, He Q, De Micheli M, Ostrowsky DB, Grezes-Besset C, Pelletier E. Integrated $\mathrm{Nd}: \mathrm{MgO}: \mathrm{LiNbO}_{3} \mathrm{FM}$ mode-locked waveguide laser. Electronic Letters. 1991;27:936-937. DOI: 10.1049/el:19910585

[72] Nouh S, Baldi P, El Hadi K, De Micheli M, Monnom G, Ostrowsky DB, Lallier E, Papuchon M. Fabrication parameter optimization of a low-threshold high-efficiency proton-exchanged waveguide laser in $\mathrm{Nd}: \mathrm{LiTaO}_{3}$. Optics Letters. 1995;20:1468-1470. DOI: $10.1364 /$ OL.20.001468

[73] Bhutta T, Chardon AM, Shepherd DP, Daran E, Serrano C, Muñoz-Yagüe A. Low phonon energy, $\mathrm{Nd}: \mathrm{LaF}_{3}$ channel waveguide lasers fabricated by molecular beam epitaxy. IEEE Journal of Quantum Electronics. 2001;37:1469-1477. DOI: 10.1109/3.958380

[74] Bausá LE, Lifante G, Daran E, Pernas PL. $\mathrm{CaF}_{2}: \mathrm{Er}^{3+}$ molecular beam epitaxial layers as optical waveguides. Applied Physics Letters. 1996;68:3242-3244. DOI: 10.1063/1.116561

[75] Gerhardt R, Kleine-Börger J, Beilschmidt L, Frommeyer M, Dötsch H, Gather B. Efficient channel-waveguide laser in Nd:GGG at $1.062 \mu \mathrm{m}$ wavelength. Applied Physics Letters. 1999;75:1210-1212. DOI: 10.1063/1.124644 
[76] Rivier S, Mateos X, Petrov V, Griebner U, Romayuk YE, Borca CN, Gardillou F, Pollnau M. $\mathrm{Tm}: \mathrm{KY}\left(\mathrm{WO}_{4}\right)_{2}$ waveguide laser. Optics Express. 2007;15:5885-5892. DOI: 10.1364/OE. 15.005885

[77] Almeida RM, Xin MD, Barbier D, Orignac X. Er ${ }^{3+}$-doped multicomponent silicate glass planar waveguides prepared by sol-gel processing. Journal of Sol-Gel Science and Technology. 1999;14:209-216. DOI: 10.1023/A:1008794202103

[78] Mao SS, Quéré F, Guizard S, Mao X, Russo RE, Petite G, Martin P. Dynamics of femtosecon laser interactions with dielectrics. Applied Physics A. 2004;79:1695-1709. DOI: 10.1007/s00339-004-2684-0

[79] Schaffer CB, Brodeur A, Mazur E. Laser-induced breakdown and damage in bulk transparent materials induced by tightly focused femtosecond laser pulses. Measurement Science and Technology. 2001;12:1784-1794. DOI: 10.1088/0957-0233/12/11/305

[80] Lancry M, Poumellec B, Chahid-Erraji A, Beresna M, Kazansky PG. Dependence of the femtosecond laser refractive index change thresholds on the chemical composition of doped-silica glasses. Optical Materials Express. 2011;1:711-723. DOI: 10.1364/ OME.1.000711

[81] Ogino M, Ohuchi F, Hench LL. Compositional dependence of the formation of calcium phosphate films on bioglass. Journal of Biomedical Materials Research. 1980;14:55-64. DOI: $10.1002 / j b m .820140107$

[82] Kokubo T, Takadama H. How useful is SBF in predicting in vivo bone bioactivity? Biomaterials. 2006;27:2907-2915. DOI: 10.1016/j.biomaterials.2006.01.017

[83] De Aza PN, Guitián F, De Aza S. A new bioactive material which transforms in situ into hydroxyapatite. Acta Materialia. 1998;46:2541-2549. DOI: 10.1016/S1359-6454(98)80038-4

[84] Yong D, Zhonghon J. Prediction of glass formation regions by calculation of eutectic using ideal-solution model. Journal of the Americam Ceramic Society. 1991;74:22952298. DOI: 10.1111/j.1151-2916.1991.tb08299.x

[85] Lu ZP, Liu CT. A new approach to understanding and measuring glass formation in bulk amorphous materials. Intermetallics. 2004;12:1035-1043. DOI: 10.1016/j.intermet. 2004.04.032

[86] Magallanes-Perdomo M, Pena P, De Aza PN, Carrodeguas RG, Rodríguez MA, Turrillas X, De Aza S, De Aza AH. Devitrification studies of wollastonite-tricalcium phosphate eutectic glass. Acta Biomaterialia. 2009;5:3057-3066. DOI: 10.1016/j.actbio.2009.04.026

[87] Pardo JA, Peña JI, Merino RI, Cases R, Larrea A, Orera VM. Spectroscopic properties of $\mathrm{Er}^{3+}$ and $\mathrm{Nd}^{3+}$ doped glasses with $0.8 \mathrm{CaSiO}-0.2 \mathrm{Ca}_{3}\left(\mathrm{PO}_{4}\right)_{2}$ eutectic composition. Journal of Non-Crystalline Solids. 2002;298:23-31. DOI: 10.1016/S0022-3093(01)01043-2

[88] Arias-Egido E, Sola D, Pardo JA, Martínez JI, Cases R, Peña JI. On the control of optical transmission of aluminosilicate glasses manufactured by the laser floating zone technique. Optical Materials Express. 2016;6:2413-2421. DOI: 10.1364/OME.6.002413 
[89] Sola D, Ester FJ, Oliete PB, Peña JI. Study of the stability of the molten zone and the stresses induced during the growth of $\mathrm{Al}_{2} \mathrm{O}_{3}-\mathrm{Y}_{3} \mathrm{Al}_{5} \mathrm{O}_{12}$ eutectic composite by the laser floating zone technique. Journal of the European Ceramic Society. 2011;31:1211-1218. DOI: 10.1016/j.jeurceramsoc.2010.08.022

[90] Trapp HJL, Stevels JM. Conventional and invert glasses containing Titania, I. Physics and Chemistry of Glasses. 1960;1:107-118

[91] Weber MJ. Science and technology of laser glass. Journal of Non-Crystalline solids. 1990;123:208-222. DOI: 10.1016/0022-3093(90)90786-L

[92] Sola D, Conejos D, De Mendivil JM, SanMartín LO, Lifante G, Peña JI. Directional solidification, thermo-mechanical and optical properties of $\left(\mathrm{Mg}_{\mathrm{x}} \mathrm{Ca}_{1-\mathrm{x}}\right)_{3} \mathrm{Al}_{2} \mathrm{Si}_{3} \mathrm{O}_{12}$ glasses doped with $\mathrm{Nd}^{3+}$ ions. Optics Express. 2015;23:26356-26368. DOI: 10.1364/OE.23.026356

[93] Sola D, Balda R, Peña JI, Fernández J. Site-selective laser spectroscopy of $\mathrm{Nd}^{3+}$ ions in $0.8 \mathrm{CaSiO}_{3}-0.2 \mathrm{Ca}_{3}\left(\mathrm{PO}_{4}\right)_{2}$ biocompatible eutectic glass-ceramics. Optics Express. 2012;20:10701-10711. DOI: 10.1364/OE.20.010701

[94] Sola D, Balda R, Peña JI, Fernández J. Time-resolved fluorescence line-narrowing of $\mathrm{Eu}^{3+}$ in biocompatible eutectic glass-ceramics. Optics Express. 2013;21:6561-6571. DOI: 10.1364/OE.21.006561

[95] Sola D, Paulés D, Grima L, Anzano J. Laser-induced breakdown spectroscopy (LIBS) for monitoring the formation of hydroxyapatite porous layers. Materials. 2017;10:1395. DOI: $10.3390 / \mathrm{ma10121395}$

[96] Dekker P, Ams M, Marshall GD, Little DJ, Withford MJ. Annealing dynamics of waveguide Bragg gratings: Evidence of femtosecond laser induced colour centres. Optics Express. 2010;18:3274-3283. DOI: 10.1364/OE.18.003274

[97] Benayas A, Jaque D, McMillen B, Chen KP. Thermal stability of microstructural and optical modifications induced in sapphire by ultrafast laser filamentation. Journal of Applied Physics. 2010;107:033522. DOI: 10.1063/1.3280029

[98] Sánchez-Morales ME, Vazquez GV, Lifante G, Cantelar E, Rickards J, Trejo-Luna $\mathrm{R}$. Analysis of the absorption coefficient in carbon implanted $\mathrm{Nd}: \mathrm{YVO}_{4}$ by an annealing process. Optics and Spectroscopy. 2011;110:885-889. DOI: $10.1134 / S 0030400 X 11060142$

[99] Townsend PD, Chandler PJ, Zhang L. Optical Effects on Ion Implantation. Cambridge: Cambridge Studies in Modern Optics; 1994. DOI: 10.1017/CBO9780511599781

[100] Ródenas A, Torchia GA, Lifante G, Cantelar E, Lamela J, Jaque F, Roso L, Jaque D. Refractive index change mechanisms in femtosecond laser written ceramic Nd:YAG waveguides: Micro-spectroscopy experiments and beam propagation calculations. Applied Physics B. 2009;95:85-96. DOI: 10.1007/s00340-008-3353-3

[101] Ródenas A, Maestro LM, Ramírez MO, Torchia GA, Roso L, Chen F, Jaque D. Anisotropic lattice changes in femtosecond laser inscribed $\mathrm{Nd}^{3+}: \mathrm{MgO}: \mathrm{LiNbO}_{3}$ optical waveguides. Journal of Applied Physics. 2009;106:013110. DOI: 10.1063/1.3168432 
